\title{
Analyzing Listening and Speaking Activities of Iranian EFL Textbook Prospect 3 Through Bloom's Revised Taxonomy
}

\author{
Maryam Mizbani \\ Department of English, Islamic Azad University, Isfahan (Khorasgan) Branch, Isfahan, Iran \\ E-mail: maryam.mizbani@yahoo.com \\ Azizeh Chalak (Corresponding author) \\ Department of English, Islamic Azad University, Isfahan (Khorasgan) Branch, Isfahan, Iran \\ E-mail: azichalak@gmail.com
}

Doi:10.7575/aiac.alls.v.8n.3p.38

URL: http://dx.doi.org/10.7575/aiac.alls.v.8n.3p.38
Received: $13 / 03 / 2017$

Accepted: 24/05/2017

\begin{abstract}
Some significant components are essential in teaching a language. Among these, textbooks are the most significant ones and must be considered seriously. Textbooks play an important role in EFL teaching and learning because they can provide ready-made materials to both teachers and students. Besides, if textbooks aren't used appropriately, they may spoil the process of teaching. This study aimed at analyzing listening and speaking activities of the textbook Prospect 3 which is used for Junior High School third graders in order to investigate in which level of lower or higher of the learning objectives related to Bloom's (2001) Revised Taxonomy of Cognitive Domain they would be classified. The findings revealed that all of the activities of listening and speaking skills were classified as the low level of cognitive complexity and could not train the students of this grade for high levels of learning objectives. Hence the teachers should employ extra activities to make the students perform in higher levels of thinking skills and book designers should improve the content of the textbook to cover the higher levels of the cognitive domain.
\end{abstract}

Keywords: Bloom's Cognitive Domain, listening, speaking, textbook analysis, thinking skills

\section{Introduction}

English as an international language and a means of communication among different nations in the world helps the countries in the process of modernization. The purpose of teaching English is to improve four language skills; listening, speaking, reading, and writing. These four language skills enable students to take part in an information exchange and establish a relationship among themselves and to obtain the recent knowledge of sciences in different fields. The teachers must develop the learners' four language skills so that they can use language for communication and to express their mind, their feelings, and their ideas. All of these four skills are important and shouldn't be ignored. Between these four skills, reading and listening are receptive skills and speaking and writing are productive ones.

Listening can be described as receiving the sounds of speech via words and sentences. While listening, we use our ears to receive individual sounds among which are letters, stress, rhythm, and pauses and we use our brain to convert these sounds into messages that are meaningful. In any language focus and attention are two important elements for listening. People who are not able to concentrate are typically poor listeners. Listening in a second language demands even greater focus. On the other hand, the ability to speak skillfully is essential because it provides the main and distinct advantages for the speaker. So putting words together in a meaningful way to reflect ideas, opinions, and feelings is very advantageous.

The primary means with which the students interact the materials outside the class is a textbook. So choosing a textbook is a critical decision to make when planning a course. Cunningsworth (1995) stated that textbooks have several additional roles in the curriculum. Hutchinson and Torres (1994) have pointed out that textbooks may play a pivotal role in innovation.

The students are supposed to become the effective and skillful thinkers in the modern world. Thinking validates the obtained knowledge and hence the individuals will be able to create new knowledge and to build ideas and make connections between them. Marksberry (1963) has explained that the curriculum must provide thinking skills and improve thinking methods together with knowledge. By the same token, teachers must provide students with the knowledge and teach them how to think. One of the framework used for detecting the level of thinking of the contents of the textbooks is Blooms' (2001) Revised Taxonomy of Cognitive Domain. Bloom (1956) who was an educational psychologist developed a framework in order to facilitate the exchange of test items among faculties of various universities in the worlds to create banks of items for measuring the same educational objectives (Krathwohl, 2002). The taxonomy was including the levels of Knowledge, Comprehension, Application, Analysis, Synthesis, and 
Evaluation. Later Anderson and Krathwohl (2001) the students of Bloom, changed the original framework and offered the revised taxonomy which has been shown in Figure 1.
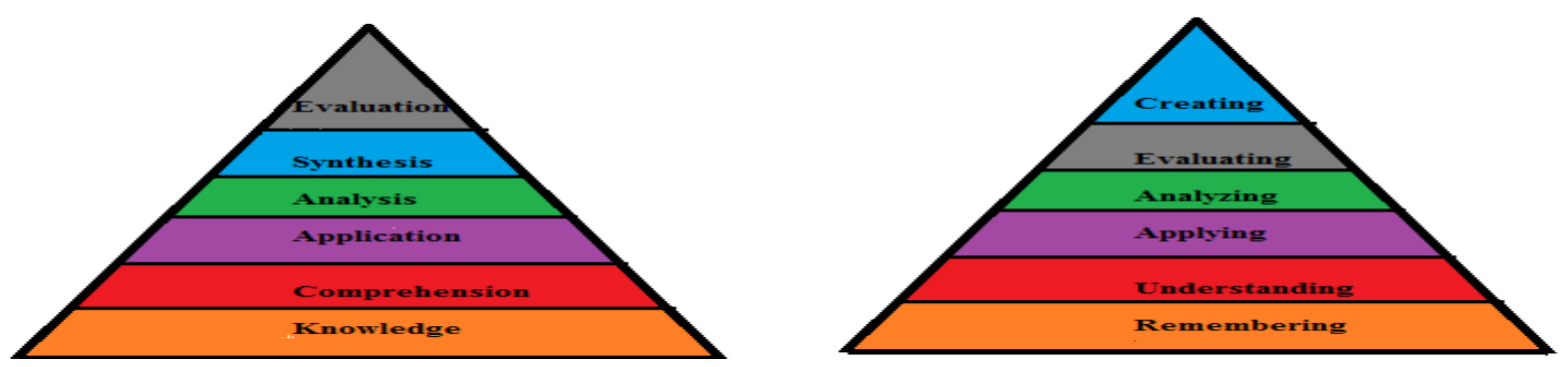

Figure 1. Bloom's (1956/2001) Original vs. Revised Taxonomy of Cognitive Domain.

As Krathwohl said the revised version included two dimensions of Knowledge and Cognitive Process (see Table 1). The levels were ordered from the simple to the most complex and each stage was a prerequisite to the next succeeding stage. The Knowledge Dimension includes a) Factual Knowledge which is knowledge of terminology and specific details; b) Conceptual Knowledge which is knowledge about the interrelationship among basic elements in a structure; c) Procedural Knowledge that means knowledge of different process and procedures; and d) Metacognitive Knowledge which means awareness and knowledge about one's own cognition and thinking.

Moreover, the Cognitive Process Dimension includes a) Remember which means recalling and remembering the specific facts and details; b) Understand which means explaining and classifying the information; c) Apply which means executing the information in a new way; d) Analyze which means breaking the information into its main parts; e) Evaluate which means making decision based on in-depth reflection; and f) Create that is creating new information.

Table 1. Bloom's (2001) Revised Taxonomy of Cognitive Domain

\begin{tabular}{lcccccc}
\hline Knowledge & \multicolumn{7}{c}{ Cognitive Process Dimension } \\
\cline { 2 - 7 } $\begin{array}{l}\text { Dimension } \\
\text { A. Factual }\end{array}$ & A1 & A2 & A3 & A4 & A5 & A6 \\
$\begin{array}{l}\text { Knowledge } \\
\text { B. Conceptual }\end{array}$ & B1 & B2 & B3 & B4 & B5 & B6 \\
$\begin{array}{l}\text { Knowledge } \\
\text { C. Procedural } \\
\text { Knowledge } \\
\begin{array}{l}\text { D. Metacognitive } \\
\text { Knowledge }\end{array}\end{array}$ & C1 & C2 & C3 & C4 & C5 & C6 \\
\hline
\end{tabular}

Since five years ago, some changes have been made to the education system in Iran; thereafter, new textbooks have been published for which very few studies were conducted to evaluate their contents. This study helps to determine in which level of the cognitive complexity, speaking and listening activities of the textbook Prospect 3 are categorized and whether they are helpful to train the students for higher levels of learning objectives and thinking skills which are the important objectives and purposes in any educational system.

Textbooks have still a vital role in EFL teaching and learning by rendering useful materials to the teachers and the students. If inappropriate textbooks are used, the teachers' skills will be spoiled and the students will lose their enthusiasm. Bloom's (2001) Revised Taxonomy has been used in many studies to evaluate the material contents and learning objectives. However, there are no studies concerning the new textbook Prospect 3 to evaluate its content regarding levels of thinking skills. In this way, it was intended to investigate how much the activities of listening and speaking of the textbook satisfy higher levels of learning objectives.

\section{Literature Review}

In various studies, Bloom's Taxonomy has been used to evaluate the contents of different textbooks in the world. Risner, Nicholson, and Myhan (1991) in the analysis of the tests provided by three of the most commonly used elementary science textbooks based on Bloom's taxonomy, suggested that higher order thinking skills are not elicited by end-of-chapter tests that accompany science textbooks, indicating a gap between the stated goals of elementary science textbooks and actual published materials.

Wang and Farmer (2008) showed that Chinese instructors of adults in teaching methods used lower thinking skills consisting of the first three levels of Bloom's Taxonomy, namely, Knowledge, Comprehension, and Application. Halawi, MacCarthy, and Pires (2009) in their study to evaluate e-learning through the web on the basis of Bloom's 
Taxonomy, using 78 questionnaires demonstrated that individual and instructional factors do not play a major role in the process of learning for undergraduate students of the university.

Igbaria (2013) in his research about the textbook Horizons, sought to examine the variety seen in the cognitive levels represented by the WH-questions in the textbook according to Bloom's Taxonomy of Cognitive Domain. The study also examined the extent to which the WH-questions in the textbook emphasized high-level thinking, and whether the textbook aided students in developing the higher thinking process that the author of the textbook attempted to develop in the students. However, he stated that the author of this textbook placed emphasis mainly on the lower thinking processes of Bloom's Taxonomy.

Rahmawati and Prayogo (2013) in their study about the kinds of reading question forms found in the English textbook Interlanguage, English for Senior High School Students including yes/no question, WH-question, multiple-choice, and true-false in which WH-questions were dominant, revealed that these kind of questions were representative of Remember Factual Knowledge level that needs the lower level of thinking process.

Razmjoo and Kazempourfard (2012) in their research to evaluate Interchange series in terms of learning objectives in Bloom's Revised Taxonomy using a coding scheme, chose three units from each textbook of the Interchange series, one from the first part, one from the middle and one from the last part of each book and demonstrated that in all four books of Interchange series, the lowest level in Bloom's Revised Taxonomy, was found to be the most frequent learning level.

Zareian, Davoudi, Heshmatifar, and Rahimi (2015) in their study investigated the types and levels of questions available in two textbooks, namely, English for the Students of Sciences, and English for the Students of Engineering taught in Iranian universities based on Bloom's Revised Taxonomy of learning objectives. Their overall findings revealed that the most prevalent learning objectives pursued in these textbooks in Iran were lower order cognitive processes, that were Remembering, Understanding, and Applying.

In a research from the codification of 439 tasks and exercises of Iranian Junior High School English textbooks fulfilled by Rahpeyma and Khoshnood (2015), it was demonstrated that the most frequent learning objectives in the content of Junior High School English textbooks in Iran were lower order learning levels of Bloom's Revised Taxonomy, that were, Remember the Factual Knowledge, Apply the Conceptual Knowledge, and Apply the Factual Knowledge. Sadeghi and Mahdipour (2015) in an analysis of 6 units of the three language institute textbooks Advanced Series, demonstrated that the frequencies of the lower order cognitive domains based on Bloom's (2001) Revised Taxonomy were found to be more than the higher order skills.

The above mentioned studies revealed the results for analyzing different EFL textbooks based on Bloom's (2001) revised framework for learning objectives. With reference to the previous studies, this study intended to evaluate the textbook Prospect 3 to answer the following research questions:

1. Which elements of Bloom's (2001) Revised Taxonomy are more prevalent in speaking activities of the textbook Prospect 3, the textbook of third graders of Junior High School?

2. Which elements of Bloom's (2001) Revised Taxonomy are more prevalent in listening activities of the textbook Prospect 3 ?

3. Whether listening and speaking activities in Prospect 3, encompass an adequately wide range of intellectual and cognitive skills.

\section{Methodology}

\subsection{Design of the Study}

The present study was a descriptive and a mixed method study containing both qualitative and quantitative parts. In qualitative part, 57 activities of speaking and listening in the textbook Prospect 3 were codified based on the coding scheme of the study that was Bloom's (2001) Revised Taxonomy of Cognitive Domain. In quantitative part, the frequencies and percentages of the codes as well as a chi-square test, inter-rater, and intra-rater reliabilities were calculated. So it was a mixed method research.

\subsection{Instruments}

The instruments of the study were six levels of Bloom's (2001) Revised Taxonomy of Cognitive Domain to investigate in which levels, speaking and listening activities of the textbook were categorized. The first three levels of the Cognitive Domain which are Remember, Understand, and Apply are the low levels of the taxonomy and Analyze, Evaluate, and Create are the high levels of the Taxonomy.

\subsection{Data Collection and Data Analysis Procedures}

To collect the data, the total 57 activities of the textbook, including 30 activities of listening skills and 27 activities of speaking skills in each unit were collected. Then they were analyzed according to the coding scheme of the study. The coding categories were labeled as A1 or Remembering the Factual Knowledge, B1 or Remembering the Conceptual Knowledge, $\mathrm{C} 1$ or Remembering the Procedural Knowledge, D1 or Remembering the Metacognitive Knowledge, A2 or Understanding the Factual Knowledge, B2 or Understanding the Conceptual Knowledge, C2 or Understanding the Procedural Knowledge, D2 or Understanding the Metacognitive Knowledge, A3 or Applying the Factual Knowledge, B3 or Applying the Conceptual Knowledge, C3 or Applying the Procedural Knowledge, D3 or Applying the Metacognitive Knowledge, A4 or Analyzing the Factual Knowledge, B4 or Analyzing the Conceptual Knowledge, C4 or Analyzing the Procedural Knowledge, D4 or Analyzing the Metacognitive Knowledge, A5 or Evaluating the Factual Knowledge, B5 or Evaluating the Conceptual Knowledge, C5 or Evaluating the Procedural Knowledge, D5 or Evaluating the Metacognitive Knowledge, A6 or Creating the Factual Knowledge, B6 or Creating the Conceptual 
Knowledge, C6 or Creating the Procedural Knowledge, and D6 or Creating the Metacognitive Knowledge which are available in Bloom's (2001) Revised Taxonomy of Cognitive Domain.

After codifying the materials, the frequency and percentage of each learning objective for each level were calculated. Moreover, to determine whether there is a significant pattern in the distribution of different levels of cognitive skills of listening and speaking activities in the textbook, a chi-square test was run. Besides, for inter-rater reliability, another analyst was invited and after introducing the procedures, about $25 \%$ of the activities were codified and the agreement between two codifications was calculated which was about 0.92. In intra-rater reliability, the researcher codified about 30 random samples of the activities within a span of two weeks, then the agreement between two stages of codifications was found to be 0.98 which is perfect.

\section{Results}

The results concerning the codification of listening activities are represented in Table 2.

Table 2. The Frequency and Percentage of Codifications of Listening Activities

\begin{tabular}{|c|c|c|c|c|c|c|}
\hline & \multicolumn{5}{|c|}{ Cognitive Process Dimension } & \multirow[b]{2}{*}{ 6. Create } \\
\hline $\begin{array}{lc}\text { Knowledge } & \text { Frequency/ } \\
\text { Dimension } & \text { Percent }\end{array}$ & 1. Remember & 2. Understand & 3. Apply & 4. Analyze & 5. Evaluate & \\
\hline A. Factual & 18 & 2 & 0 & 0 & 0 & 0 \\
\hline Knowledge & $60 \%$ & $6.6 \%$ & 0.00 & 0.00 & 0.00 & 0.00 \\
\hline B. Conceptual & 0 & 10 & 0 & 0 & 0 & 0 \\
\hline Knowledge & 0.00 & $33.3 \%$ & 0.00 & 0.00 & 0.00 & 0.00 \\
\hline C. Procedural & 0 & 0 & 0 & 0 & 0 & 0 \\
\hline Knowledge & 0.00 & 0.00 & 0.00 & 0.00 & 0.00 & 0.00 \\
\hline D. Metacognitive & 0 & 0 & 0 & 0 & 0 & 0 \\
\hline Knowledge & 0.00 & 0.00 & 0.00 & 0.00 & 0.00 & 0.00 \\
\hline
\end{tabular}

As Table 2 shows the codes were ordered as A1 or Remembering the Factual Knowledge with the frequency of 18 and percentage of 60, B2 or Understanding the Conceptual knowledge with the frequency of 10 and percentage of 33.3, and A2 or Understanding the Factual knowledge with the frequency of 2 and percentage of 6.6. Table 2 demonstrates that among 24 codes of Bloom's (2001) Revised Taxonomy, only three codes were available which belonged to the lower levels of the taxonomy of cognitive domain. Figure 2 shows the results for listening activities of the textbook.

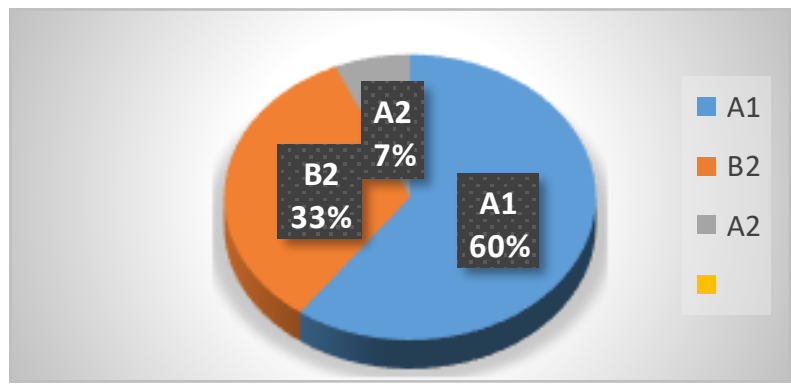

Figure 2. Learning categories of listening activities

For speaking activities, the following codifications were obtained respectively. Applying the Conceptual Knowledge or B3 with the most frequent codification of 15 and percentage of 55.5, Understanding the Conceptual Knowledge or B2 with the frequency of 10 and percentage of 37, and Remembering the Conceptual Knowledge or B1 with the last and least frequency of 2 and percentage of 7.4. These codes are available in Table 3 below.

Table 3. The Frequency and Percentage of Codifications of Speaking Activities

\begin{tabular}{lccccccc}
\hline Knowledge & Frequency/ & \multicolumn{7}{c}{ Cognitive Process Dimension } \\
\cline { 2 - 7 } Dimension & Percent & 1. Remember & 2. Understand & 3. Apply & 4. Analyze & 5. Evaluate & 6. Create \\
\hline A. Factual & 0 & 0 & 0 & 0 & 0 & 0 \\
Knowledge & 0.00 & 0.00 & 0.00 & 0.00 & 0.00 & 0.00 \\
\hline B. Conceptual & 2 & 10 & 15 & 0 & 0 & 0 & 0.00 \\
Knowledge & 7.40 & $37 \%$ & 55.5 & 0.00 & 0.00 & 0 \\
\hline C. Procedural & 0 & 0 & 0 & 0 & 0 & 0 \\
Knowledge & 0.00 & 0.00 & 0.00 & 0.00 & 0.00 & 0.00 \\
\hline D. Metacognitive & 0 & 0 & 0 & 0 & 0 & 0 \\
Knowledge & 0.00 & 0.00 & 0.00 & 0.00 & 0.00 & 0.00 \\
\hline
\end{tabular}


Table 3 shows that among the total 24 codes of the taxonomy just three codes were found for speaking activities of the textbook, all of which were categorized into the lower levels of learning objectives. Figure 3 represents the categories of speaking activities of the textbook.

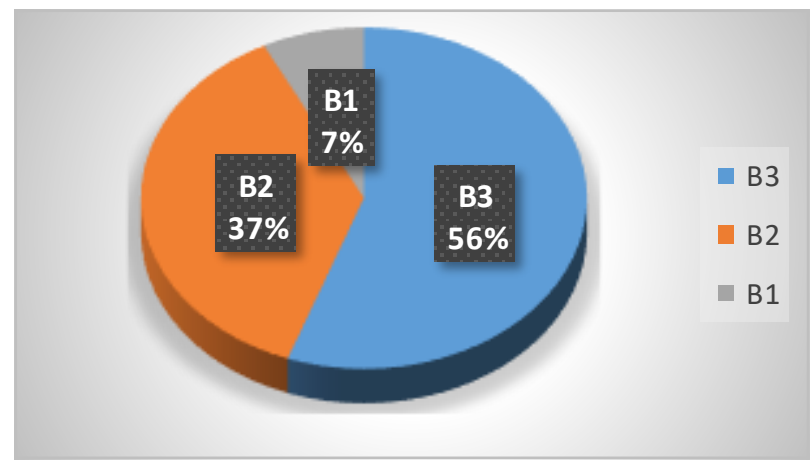

Figure 3. Learning categories of speaking activities.

If we want to represent the distribution of codifications between the two activities of listening and speaking of the textbook, Figure 4 helps to compare the codes obtained for these two skills.

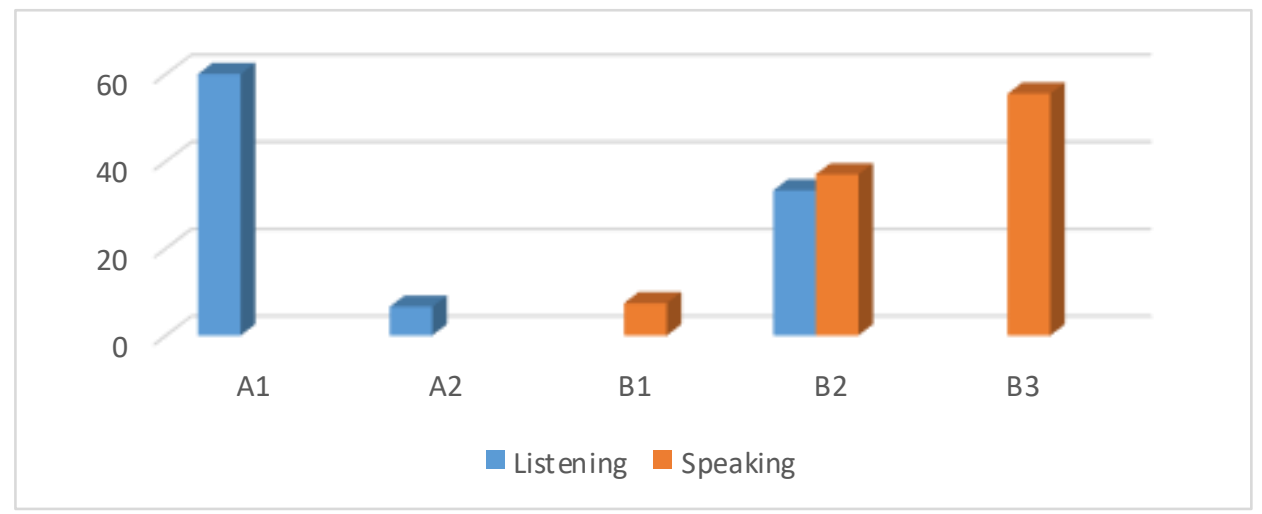

Figure 4. A comparison of percentages for listening and speaking activities

Figure 4 demonstrates that just the codification of B2 or Understanding the Conceptual Knowledge is found for both listening and speaking activities of the textbook. Moreover, in listening activities of the book, A1 or Remembering the Factual Knowledge is the most prominent codification and for speaking activities, B3 or Applying the Conceptual Knowledge is significant.

The output of chi-square test showed a significant result $(\mathrm{Sig}=0.000)$ for the distribution of codification between the two skills of listening and speaking activities in the textbook (see Table 4).

Table 4. Chi-Square Test for Listening and Speaking Activities in Terms of Coding Levels

\begin{tabular}{lcc}
\hline Chi-Square & $d f$ & Asymp.Sig \\
\hline 36.944 & 4 & 0.000 \\
\hline & $\mathrm{p} \leq 0.05$
\end{tabular}

\section{Conclusion}

Regarding the first Research Question, in listening activities of the textbook Prospect 3, three codes were found including A1 or Remembering the Factual Knowledge, B2 or Understanding the Conceptual Knowledge, and A2 or Understanding the Factual Knowledge respectively. Because all these codes belong to the lower levels of the taxonomy of Cognitive domain, it may be concluded that the listening activities of the textbook Prospect 3 only satisfy the low level of Bloom's (2001) Revised Taxonomy and the higher levels of the cognitive complexity are absolutely absent in these activities of the textbook.

For the second Research Question it should be stated that all of the three codifications found for speaking activities which are ordered as Applying the Conceptual Knowledge or B3, Understanding the Conceptual Knowledge or B2, and Remembering the Conceptual Knowledge or B1, are categorized among the lower levels of the learning objectives and again the codes of higher levels of the cognitive domain are totally absent for the speaking activities of the textbook. 
The analyses related to the third Research Question revealed that listening and speaking activities of the textbook are not responsible for fostering high levels of thinking process among the students of the third grade of Junior High School to fulfill activities such as analyzing, creating, and evaluating.

There is, therefore, a definite need for incorporating activities for EFL students to self-evaluate, practice, and critique their performance in the classroom. Moreover, L2 textbook developers need to engage EFL students in higher-order skills by adding supplementary items to the content of the textbook. As the previous research carried out by the researcher towards the activities of reading and writing skills which rendered similar results, it is recommended that the textbook designers modify the content developed for the textbook materials to engage skills such as predicting, using contextual clues, guessing meaning of words through context, interpreting texts, and evaluating a text critically.

Further research might be conducted towards the content of the textbooks Prospect 1 and Prospect 2, the textbooks of the first and the second grade of Junior High school, and Vision 1 the textbook of the first grade of Senior High School using the framework of the present study which is Bloom's (2001) Revised Taxonomy of Cognitive Domain, to explore their levels of learning objectives.

\section{References}

Anderson, L. W., \& Krathwohl, D. R. (2001). A taxonomy for learning, teaching, and assessing a revision of Bloom's Taxonomy. New York: Longman Publishing.

Bloom, B., Englehart, M., Furst, E., Hill, W., \& Krathwohl, D. (1956). Taxonomy of Educational objectives: The classification of educational goals. New York, Toronto: Longmans, Green.

Cunningsworth A. (1995). Choosing your course book. Oxford: Heinemann.

Halawi, L., McCarthy, R., \& Pires, S. (2009). An evaluation of learning on the basis of Bloom's Taxonomy. Journal of Education for Business. http://abufara.com/abufara.net/images/abook_file/An\%20Evaluation\%20of\%20.pdf

Hutchinson, T., \& Torres, E. (1994). The textbook as an agent of change. ELT Journal, 48(4), 315-328.

Igbaria, A. (2013). A content analysis of the wh-questions in the EFL textbook of Horizons. International Education Studies, 6(7).

Krathwohl, D. R. (2002). A revision of Bloom's taxonomy: An overview. Theory into Practice, 41(4), 212218. Retrieved from Marksberry, M., (1963). Foundations of creativity. New York: Harper \& Row Publishers.

Rahmawati, I., \& Prayogo, J. (2013). An analysis of reading questions in English textbook Interchange based on RBT. http://jurnal- online.um.ac.id/data/artikel/artikelDE.pdf

Rahpeyma, A., \& Khoshnood, A. (2015). The analysis of learning objectives in Iranian junior high school English textbooks based on Bloom's Revised Taxonomy. International Journal of Education \& Literacy Studies,3(2).

Razmjoo, S. A., \& Kazempourfard, E. (2012). On the representation of Bloom's Revised Taxonomy in Interchange coursebooks. The Journal of Teaching Language Skills, 4(1).

Risner, G., Nicholson, J., \& Myhan, J. (1991). Levels of questioning in current elementary textbooks. Annual Meeting of the Mid-South Educational Research Association. Lexington: Kentucky.

Sadeghi, B., \& Mahdipour, N. (2015). Evaluating ILI Advanced Series through Bloom's Revised Taxonomy. Science Journal, 36(3).

http://dergi.cumhuriyet.edu.tr/cumuscij/article/viewFile/5000121717/5000114470

Wang, v., \& Farmer, L. (2008). Adult teaching methods in China and Bloom's Taxonomy. International Journal for the Scholarship of Teaching and Learning, 2(2).

Zareian, G., Davoudi, M., Heshmatifar, Z., \& Rahimi, J. (2015). An evaluation of questions in two ESP course books based on Bloom's New Taxonomy of Cognitive Learning Domain. International Journal of Education and Research, $3(8)$. 